\title{
Management of acne
}

\section{John Kraft MD, Anatoli Freiman MD}

A cne vulgaris has a substantial impact on a patient's quality of life, affecting both self-esteem and psychosocial development. ${ }^{1}$ Patients and physicians are faced with many over-the-counter and prescription acne treatments, and choosing the most effective therapy can be confusing.

In this article, we outline a practical approach to managing acne. We focus on the assessment of acne, use of topical treatments and the role of systemic therapy in treating acne.

Acne is an inflammatory disorder of pilosebaceous units and is prevalent in adolescence. The characteristic lesions are open (black) and closed (white) comedones, inflammatory papules, pustules, nodules and cysts, which may lead to scarring and pigmentary changes (Figures 1 to 4 ). The pathogenesis of acne is multifactorial and includes abnormal follicular keratinization, increased production of sebum secondary to hyperandrogenism, proliferation of Propionibacterium acnes and inflammation., ${ }^{2,3}$

Lesions occur primarily on the face, neck, upper back and chest. ${ }^{4}$ When assessing the severity of the acne, one needs to consider the distribution (back, chest, upper arms), type and number of lesions (comedones, papules, pustules, nodules) and the presence or absence of scarring (Table 1).,.3

Different variants of acne exist, including acne conglobata, acne fulminans, acne mechanica, excoriated acne, chloracne, drug-induced acne (e.g., from anabolic steroids, corticosteroids, isoniazid, lithium, phenytoin), neonatal and infantile acne, and occupational acne. These variations have a similar clinical and histologic appearance to acne vulgaris, but they are distinguishable by clinical setting, severity and associated symptoms. The common differential diagnosis of acne includes folliculitis, keratosis pilaris, perioral dermatitis, seborrheic dermatitis and rosacea.

\section{Is there an underlying cause?}

The diagnosis of acne vulgaris is primarily clinical. ${ }^{4}$ History and physical examination can help determine if there is an underlying cause of the acne, such as an exacerbating medication or endocrinologic abnormality causing hyperandrogenism (e.g., polycystic ovarian syndrome). Other dermatologic manifestations of androgen excess include seborrhea, hirsutism and androgenetic alopecia. Endocrinologic testing is not ordered routinely for women with regular menstrual cycles. ${ }^{2.3}$ Older women, especially those with new-onset acne and other signs of androgen excess (e.g., hirsutism, androgenic alopecia, menstrual irregularities, infertility), should be tested for androgen excess with measurements of total and free serum testosterone, dihydroepiandrosterone, and luteiniz-

\section{Key points}

- Effective therapies for acne target one or more pathways in the pathogenesis of acne, and combination therapy gives better results than monotherapy.

- Topical therapies are the standard of care for mild to moderate acne.

- Systemic therapies are usually reserved for moderate or severe acne, with a response to oral antibiotics taking up to six weeks.

- Hormonal therapies provide effective second-line treatment in women with acne, regardless of the presence or absence of androgen excess.

ing and follicle-stimulating hormone levels. ${ }^{5}$ Pelvic ultrasonography may show the presence of polycystic ovaries. ${ }^{5}$ In prepubertal children with acne, signs of hyperandrogenism include early-onset accelerated growth, pubic or axillary hair, body odour, genital maturation and advanced bone age.

Treatment for acne vulgaris should aim to reduce severity and recurrences of skin lesions as well as to improve appearance. The approach depends on the severity of the acne, the treatment preferences and age of the patient, and adherence and response to previous therapy (Table 2). ${ }^{3,6}$ Various acne treatments target different steps in the pathogenesis of acne, from counteracting androgens and decreasing sebum production to preventing follicular occlusion, reducing $P$. acnes proliferation and decreasing inflammation.

Many research studies on acne therapies are small trials comparing the active drug with placebo or larger studies comparing different formulations of the same drug.

\section{How well do topical treatments work?}

Topical therapy is the standard of care for mild to moderate acne. ${ }^{3}$ Retinoids and antimicrobials such as benzoyl peroxide and antibiotics are the mainstay of topical acne therapy. Such treatments are active at application sites, and they can prevent new lesions. ${ }^{4}$ The main side effect is local irritation. Gels, pledgets (medication-soaked pads), washes and solutions tend to be drying and are helpful for oily skin. Lotions, creams and ointments are beneficial for dry, easily irritated skin. Most topical preparations require at least six to eight weeks before an improvement is seen; they may be used for years as needed. ${ }^{6}$

From the Division of Dermatology, University of Toronto, Toronto, Ont.

CMAJ 2011. DOI:10.1503/cmaj.090374 


\section{Retinoids}

The main target of acne treatment is the microcomedone. Topical retinoid therapy acts on follicular keratinocytes to prevent excessive cornification and follicular blockage. ${ }^{4}$ It may also reduce the release of proinflammatory cytokines. Such therapy decreases the number of comedones and inflammatory lesions by $40 \%$ to $70 \%$. $^{2}$ The most common side effect is irritation with erythema and scaling. Patients should be instructed to apply very small amounts initially. Optimal response occurs after 12 weeks. ${ }^{7}$ Continuous maintenance therapy can prevent flares. ${ }^{3}$

The most commonly available topical retinoids are tretinoin, adapalene and tazarotene. A meta-analysis of five multicentre randomized investigator-blind trials involving 900 patients showed adapalene $0.1 \%$ gel to be as effective as, but less irritating than, tretinoin $0.025 \%$ gel. ${ }^{8}$ Different concentrations of retinoids affect tolerability. One commonly used approach is to start with the lowest concentration and increase as tolerated.

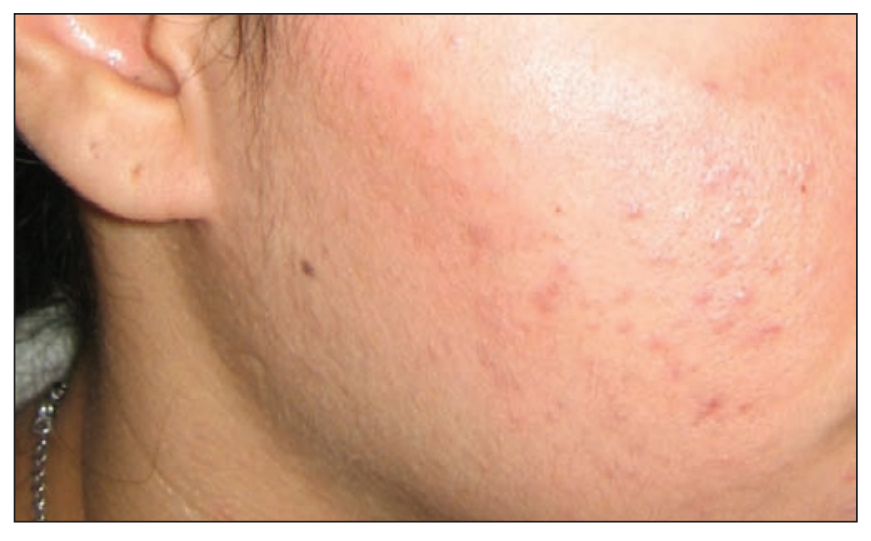

Figure 1: Grade I (mild) acne showing comedones with few inflammatory papules and pustules.

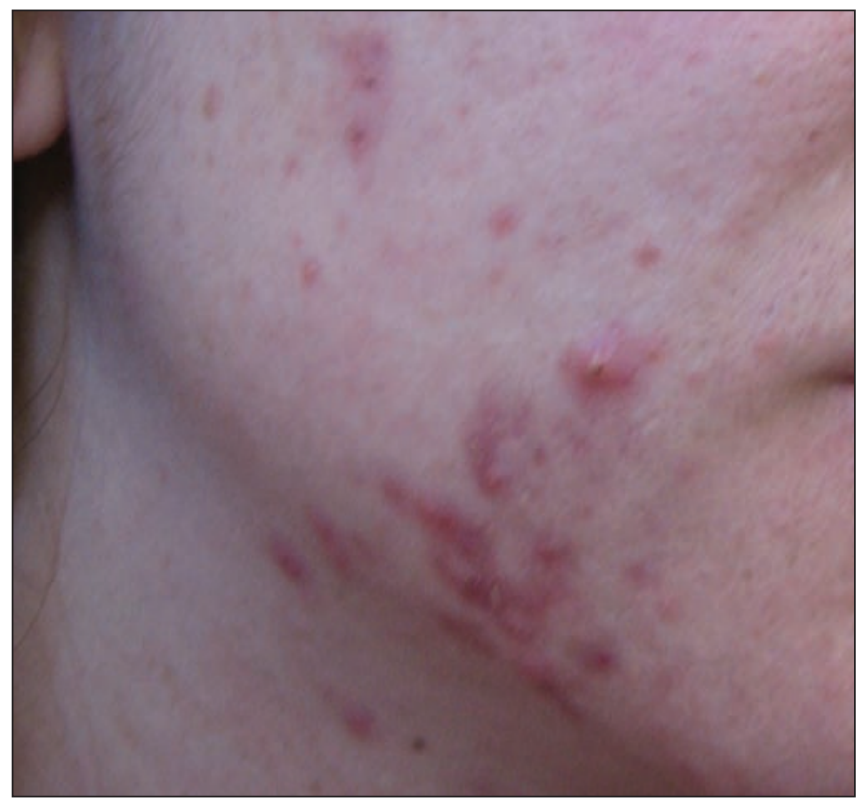

Figure 2: Grade II (moderate) acne showing papules and pustules.

\section{Antimicrobials}

Topical antimicrobials, including benzoyl peroxide and antibiotics, are effective in treating inflammatory disease. ${ }^{3,4}$ Benzoyl peroxide is a bactericidal agent that prevents the resistance of $P$. acnes to antibiotic therapy ${ }^{9}$ and has moderate comedolytic and anti-inflammatory properties. It is available in various topical preparations, ranging in strength from $2.5 \%$ to $10.0 \%$. Any strength can be used initially, although it may be more prudent to start with a lower concentration; stronger preparations are more irritating and not necessarily more effective. ${ }^{10}$ Benzoyl peroxide kills $P$. acnes by releasing oxygen within the follicle. It can be fast-acting, with a response as early as five days. ${ }^{4}$ The main drawback is that it is a potent bleaching

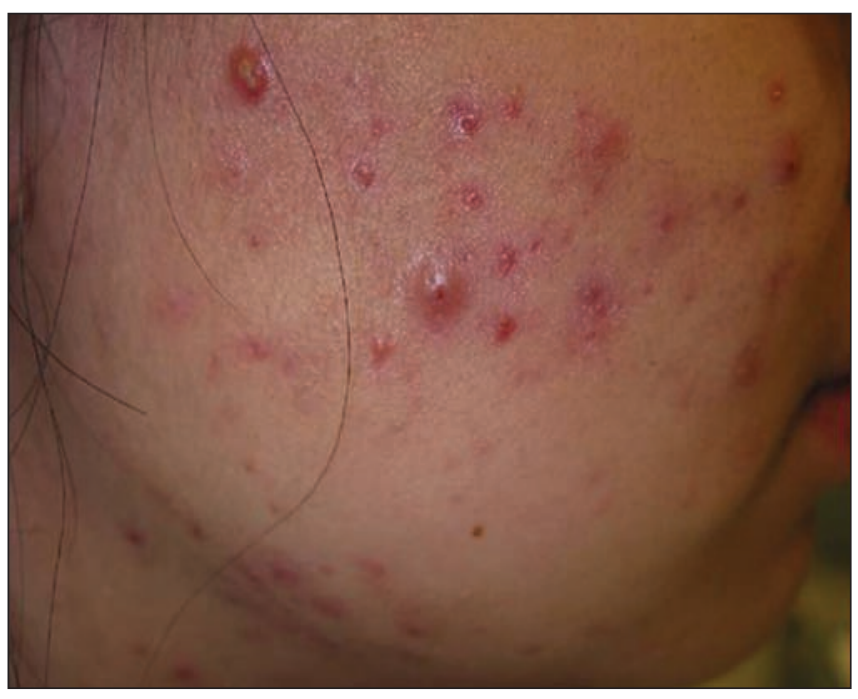

Figure 3: Grade III (moderately severe) acne showing numerous large painful nodules and pustules as well as some inflamed nodules.

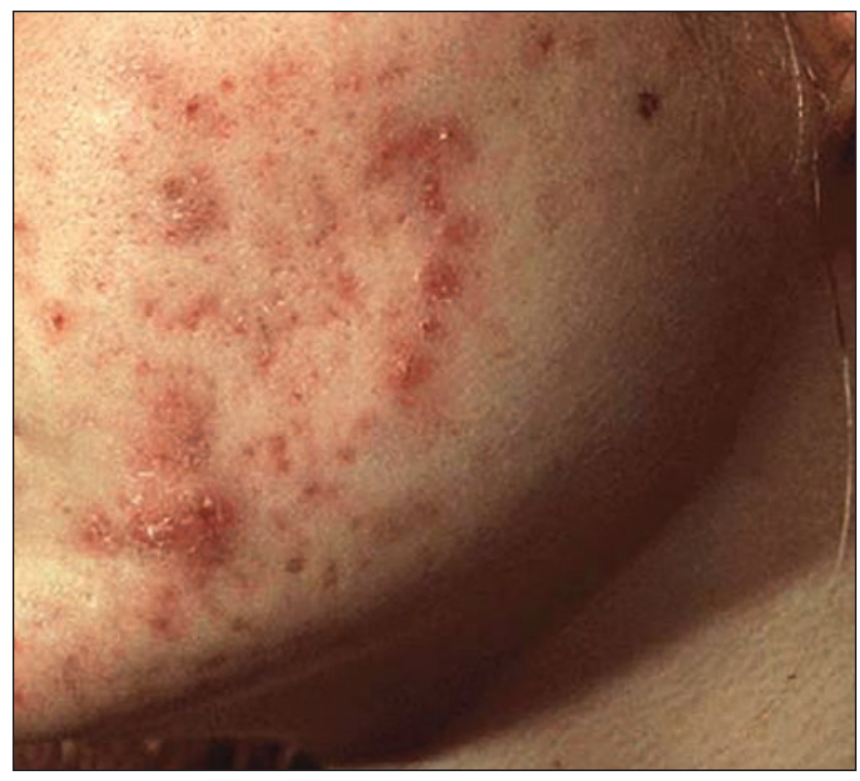

Figure 4: Grade IV (severe) acne showing many large inflamed nodules and pustules as well as scarring. 
agent. ${ }^{2}$ Patients should be warned that fabrics that come in contact with benzoyl peroxide, including towels, bed sheets and clothing, may be bleached.

Topical erythromycin and clindamycin are generally welltolerated and have been shown to reduce inflammatory lesions by $46 \%$ to $70 \%$ in several randomized controlled trials. ${ }^{2}$ Monotherapy with topical antibiotics should not be used routinely beause $P$. acnes may become resistant within one month after daily treatment has begun. ${ }^{6}$ Some argue that this resistance is not relevant because the antibiotics (e.g., clindamycin, tetracyclines, erythromycin) also have intrinsic anti-inflammatory and antimicrobial effects. ${ }^{11}$ However, antibiotic-resistant Staphylococcus epidermidis and Staphylococcus aureus may also develop with monotherapy; resistance can be avoided when a topical antibiotic is combined with benzoyl peroxide. ${ }^{12}$

\section{Combination therapy}

Combination therapy, for example with retinoids and antibiotics, is more effective than either agent used alone..$^{13}$ However, the agents should be applied at separate times, unless they are known to be compatible. ${ }^{3}$ Benzoyl peroxide may oxidize a retinoid such as tretinoin if it is applied simultaneously. ${ }^{14}$ A 12 week randomized controlled trial involving 249 patients with mild to moderate acne showed treatment with adapalene gel $0.1 \%$ and clindamycin $1.0 \%$ to be superior to that with clindamycin $1.0 \%$ used alone..$^{15}$ If inflammatory lesions are present, topical antibiotics containing benzoyl peroxide should be combined with a topical retinoid (e.g., topical antibiotic with benzoyl peroxide in the morning and retinoid at night). A review of three clinical studies with 1259 patients showed that a combination of clindamycin $1 \%$ and benzoyl peroxide $5 \%$ was more effective than either drug used alone in reducing lesions and suppressing $P$. acnes. ${ }^{16}$

\section{Over-the-counter therapy}

Before seeing a physician, patients frequently use over-thecounter therapies for their acne. Such treatments may be more accessible, cosmetically elegant, less expensive and less irritating than prescription therapies. ${ }^{17}$ However, there is insufficient evidence to evaluate and compare the efficacy of overthe-counter formulations. ${ }^{2}$

The most popular over-the-counter products, such as Proactiv, contain benzoyl peroxide but at lower concentrations than most prescription-strength products. Proactiv, a system of cleansing products in which benzoyl peroxide $2.5 \%$ is the active ingredient, is claimed to enhance compliance by providing a cosmetically elegant product that also minimizes irritation. The makers of Proactiv also market Gentle Formula, which replaces benzoyl peroxide with salicylic acid for people with allergy or intolerance. There have been few studies assessing the efficacy of the Proactiv system. In one open-label study of 23 patients with mild to moderate acne, inflammatory lesions were reduced by $39 \%$ in patients using a combination of butenifine (an allylamine) and benzoyl peroxide compared with $34 \%$ in those using Proactiv. ${ }^{18}$

Salicylic acid $2 \%$ wash is moderately effective but less potent than a topical retinoid in acne therapy. Although it has been used for many years, well-designed trials of its safety and efficacy are lacking. The evidence for the use of topical zinc, resorcinol, sulfur and aluminum chloride is also either limited or negative.

There is no clear evidence that acne vulgaris is related to poor hygiene or that frequent face washing lessens acne. Patients should be instructed to wash their face gently with warm water and mild soap twice daily; rough scrubbing can cause new lesions because of follicular rupture. The only antibacterial soaps that may be effective are those containing benzoyl peroxide. ${ }^{19}$

Patients should ensure that their facial products, including sunscreens, are noncomedogenic. They should also avoid oil-based makeup. Some topical acne products contain a sunscreen.

\section{When should systemic therapy be started?}

Patients with mild acne can be treated with topical therapies; however, those with moderate to severe acne will require systemic therapy. Oral antibiotic treatment, hormonal therapies and isotreretinoin are the mainstay systemic therapies for acne.

\section{Antibiotics}

When topical agents are insufficient or not tolerated, or in cases of moderate to severe acne, especially when the chest, back and shoulders are involved, systemic antibiotics are often considered the next line of treatment (Table 3). ${ }^{20,21}$ However, regular use of a combination of topical antibiotics and benzoyl peroxide may be similarly effective, as shown in a randomized controlled trial of five antimicrobial regimens. ${ }^{22}$

Response to oral antibiotics is usually seen after at least six weeks of therapy. ${ }^{4}$ If control is maintained for several months, the antibiotic may be discontinued gradually and only the topical therapy continued. Systemic antibiotics should not be used to treat mild acne because of the risk of increasing resistance. ${ }^{23,24}$ The additional use of nonantibiotic topical agents in combination with oral antibiotics should be considered. ${ }^{4}$ Topical retinoids with oral antibiotics may give a faster response and be more effective than either drug used alone. ${ }^{3}$

Treatment with tetracyclines and erythromycin reduces $P$. acnes within the follicles, thereby inhibiting production of bacterial-induced inflammatory cytokines. ${ }^{25}$ These agents also have inherent anti-inflammatory effects, such as suppressing

Table 1: Grading severity of acne $\mathrm{e}^{2,3}$

\begin{tabular}{lll}
\hline Grade & \multicolumn{1}{c}{ Severity } & \multicolumn{1}{c}{ Clinical findings } \\
\hline I & Mild & $\begin{array}{l}\text { Open and closed comedones } \\
\text { with few inflammatory papules } \\
\text { and pustules }\end{array}$ \\
II & Moderate & $\begin{array}{l}\text { Papules and pustules, mainly on } \\
\text { face }\end{array}$ \\
III & $\begin{array}{l}\text { Moderately } \\
\text { severe }\end{array}$ & $\begin{array}{l}\text { Numerous papules and pustules, } \\
\text { and occasional inflamed nodules, } \\
\text { also on chest and back } \\
\text { Many large, painful nodules and } \\
\text { pustules }\end{array}$ \\
\hline IV & Severe & \\
\hline
\end{tabular}


leukocyte chemotaxis and bacterial lipase activity. Minocycline and doxycycline also inhibit cytokines and matrix metalloproteinases that are thought to promote inflammation and tissue breakdown ${ }^{26}$ Although $P$. acnes has a resistance rate to tetracyclines of $20 \%$ to $60 \%$, it is uncertain if this is significant in the treatment of acne..$^{27,28}$

Oral antibiotics have been shown to be effective in reducing the number of inflammatory lesions (52\% to $67 \%$ reduction), but this is based on limited evidence. ${ }^{3}$ Higher doses can be tried if a patient seeks better control. Doxycycline and minocycline are considered more effective than tetracycline. ${ }^{29}$ Erythromycin is reserved for patients in whom tetracyclines are contraindicated (e.g., pregnant women and children under nine years of age), although the development of resistance to erythromycin is more common than with the other antibiotics. ${ }^{23}$

\section{Hormonal therapies}

Hormonal agents provide effective second-line treatment in women with acne regardless of underlying hormonal abnormalities..$^{30}$ It is not necessary to demonstrate androgen excess to achieve a benefit from antiandrogen therapy. Clinical observation suggests that deep-seated nodules on the lower face and neck are especially responsive to hormonal therapy. ${ }^{6}$

Table 2: Approach to therapy for acne vulgaris ${ }^{3,6}$

\begin{tabular}{|c|c|c|}
\hline \multirow{2}{*}{$\begin{array}{l}\text { Severity; } \\
\text { clinical findings }\end{array}$} & \multicolumn{2}{|c|}{ Treatment options } \\
\hline & First line & Second line \\
\hline \multicolumn{3}{|l|}{ Mild } \\
\hline Comedonal & Topical retinoid & $\begin{array}{l}\text { Alternative topical retinoid } \\
\text { Salicylic acid washes }\end{array}$ \\
\hline Papular/pustular & $\begin{array}{l}\text { Topical retinoid } \\
\text { Topical antimicrobial } \\
\text { - benzoyl peroxide } \\
\text { - clindamycin } \\
\text { - erythromycin } \\
\text { Combination products }\end{array}$ & $\begin{array}{l}\text { Alternative topical retinoid } \\
\text { plus alternative topical } \\
\text { antimicrobial } \\
\text { Salicylic acid washes }\end{array}$ \\
\hline \multicolumn{3}{|l|}{ Moderate } \\
\hline Papular/pustular & $\begin{array}{l}\text { Oral antibiotics } \\
\text { - tetracyclines } \\
\text { - erythromycin } \\
\text { - trimethoprim- } \\
\text { sulfamethoxazole } \\
\text { Topical retinoid } \\
\pm \text { benzoyl peroxide }\end{array}$ & $\begin{array}{l}\text { Alternative oral antibiotic } \\
\text { Alternative topical retinoid } \\
\text { Benzoyl peroxide }\end{array}$ \\
\hline Nodular & $\begin{array}{l}\text { Oral antibiotic } \\
\text { Topical retinoid } \\
\pm \text { benzoyl peroxide }\end{array}$ & $\begin{array}{l}\text { Oral isotretinoin } \\
\text { Alternative oral antibiotic } \\
\text { Alternative topical retinoid } \\
\text { Benzoyl peroxide }\end{array}$ \\
\hline Severe & Oral isotretinoin & $\begin{array}{l}\text { High-dose oral antibiotic } \\
\text { Topical retinoid (also } \\
\text { maintenance therapy) }\end{array}$ \\
\hline & & Benzoyl peroxide \\
\hline
\end{tabular}

Note: In women with acne, oral contraceptives or androgen receptor blockers (e.g., spironolactone) may be used in addition to the above treatment options.
Clinical trials have shown that estrogen-containing oral contraceptives can be helpful; ${ }^{31-33}$ the various formulations are thought to decrease levels of free testosterone by increasing sex-hormone-binding globulin and are considered equally effective. The choice of combined oral contraceptive should be based on a patient's tolerance and potential side effects. It is not known whether other estrogen-containing contraceptives (e.g., vaginal rings, transdermal patches) are effective. Contraceptives containing only progesterone may worsen acne. ${ }^{4}$

A randomized controlled trial with 128 women showed a reduction in acne lesions of $63 \%$ with $35 \mu \mathrm{g}$ ethinylestradiol and $3 \mathrm{mg}$ drospirenone and a 59\% reduction with $35 \mu \mathrm{g}$ ethinylestradiol and $2 \mathrm{mg}$ cyproterone acetate. ${ }^{34}$ Antiandrogen therapy is usually needed for at least three to six months to see significant improvement.

The oral antiandrogen spironolactone can be added if oral contraceptives are not effective. ${ }^{3}$ Spironolactone is a $5 \alpha$-reductase inhibitor when administered at higher doses. ${ }^{35}$ Spironolactone, used alone or as an adjunct at doses of $50-200 \mathrm{mg} / \mathrm{d}$, has been shown to be effective in improving acne, but this is based on limited evidence. ${ }^{2}$ However, patients should be warned about possible side effects, including hyperkalemia, menstrual irregularities and feminization of a male fetus. Antiandrogen therapy alone may be successful, but in less than half of women; ${ }^{36}$ the acne may recur when it is discontinued. Combination therapy with topical agents or oral antibiotics provides substantially more benefit. ${ }^{37}$

\section{Isotretinoin}

Isotretinoin affects all causative mechanisms of acne - it changes abnormal follicular keratinization, decreases sebum production by $70 \%$, decreases $P$. acnes colonization and is anti-inflammatory. ${ }^{38}$ Indications for isotretinoin include scarring disease, severe nodulocystic acne and less than 50\% improvement with oral antibiotics or hormonal therapies after four months..$^{38}$ Isotretinoin therapy must be monitored carefully because adverse effects include potent teratogenicity, hypertriglyceridemia and pancreatitis, hepatoxicity, blood dyscrasias, hyperostosis, premature epiphyseal closure and night blindness. An association with severe skin reactions, such as erythema multiforme, Stevens-Johnson syndrome and toxic epidermal necrolysis, has been reported. ${ }^{39}$ Although a causal relationship has not been shown, patients must be warned about depression, suicidal thoughts and psychosis, and monitored closely. ${ }^{40}$

Before a patient starts oral isotretinoin therapy, baseline blood work is recommended. ${ }^{38}$ This testing includes serum blood lipid measurements, complete blood count and differential, liver 
enzyme tests and blood glucose levels (and a pregnancy test for women of child-bearing age). ${ }^{41}$ These tests should be repeated at monthly intervals during treatment. In women of childbearing age, two forms of birth control should be used during and for one month after therapy, unless the patient has had a hysterectomy or is sexually abstinent. ${ }^{41}$

Cutaneous side effects of isotretinoin include dry eyes, nose and lips, and dermatitis. Patients should use artificial tears, and generous amounts of moisturizer on the nose, lips and skin.

According to a 10-year follow-up study of 88 patients, those who had received a cumulative dose of isotreretinoin $120-150 \mathrm{mg} / \mathrm{kg}$ had a substantially lower rate of recurrence (30\%) than those who received less than $120 \mathrm{mg} / \mathrm{kg}(82 \%){ }^{42}$ An additional course can be prescribed for patients in whom the acne recurs after isotretinoin is discontinued.

\section{What about alternative therapies?}

Herbal therapies such as tea tree oil, and topical and oral ayurvedic compounds seem to be well tolerated; however, there are limited data about their efficacy and safety in treat-

Table 3: Oral antibiotic therapy for acne vulgaris ${ }^{20,21}$

\begin{tabular}{|c|c|}
\hline Antibiotic, dose & Notes \\
\hline $\begin{array}{l}\text { Tetracycline } \\
250-500 \mathrm{mg} \text { twice } \\
\text { daily }\end{array}$ & $\begin{array}{l}\text { - Inexpensive } \\
\text { - Contraindicated in pregnant women } \\
\text { or in children under nine years of age } \\
\text { - Chelated by antacids and milk; to be } \\
\text { taken on empty stomach }\end{array}$ \\
\hline $\begin{array}{l}\text { Minocycline } \\
50-200 \mathrm{mg} \text { daily }\end{array}$ & $\begin{array}{l}\text { - Can be taken with food } \\
\text { - Contraindicated in pregnant women } \\
\text { or in children under nine years of age } \\
\text { - Adverse reactions: dizziness, pigment } \\
\text { changes, hepatitis, lupus-like } \\
\text { reactions }\end{array}$ \\
\hline $\begin{array}{l}\text { Doxycycline } \\
100-200 \text { mg daily }\end{array}$ & $\begin{array}{l}\text { - Can be taken with food } \\
\text { - Acceptable for use in patients with } \\
\text { renal failure } \\
\text { - Contraindicated in pregnant women } \\
\text { or in children under nine years of age } \\
\text { - Adverse reactions: gastrointestinal } \\
\text { upset; phototoxicity (greatest of all } \\
\text { tetracyclines) }\end{array}$ \\
\hline $\begin{array}{l}\text { Erythromycin } \\
500 \text { mg twice daily }\end{array}$ & $\begin{array}{l}\text { - Safe in pregnant women and } \\
\text { children } \\
\text { - Adverse reaction: may cause } \\
\text { gastrointestinal upset } \\
\text { - } 42 \% \text { of patients may show resistance } \\
\text { to Propionibacterium acnes }{ }^{18}\end{array}$ \\
\hline $\begin{array}{l}\text { Trimethoprim/ } \\
\text { sulfamethoxazole } \\
80 / 400 \mathrm{mg} \text { or } \\
160 / 800 \mathrm{mg} \text { four } \\
\text { times a day }\end{array}$ & $\begin{array}{l}\text { - Useful in patients resistant to other } \\
\text { antibiotics } \\
\text { - Adverse reactions: } 3 \%-4 \% \text { of } \\
\text { patients experience rash; }{ }^{21} \text { risk of } \\
\text { serious skin reactions, such as } \\
\text { Stevens-Johnson syndrome }\end{array}$ \\
\hline
\end{tabular}

ing acne. ${ }^{3}$ One clinical trial showed that topical tea tree oil was effective but had a slower onset of action than traditional topical agents. ${ }^{43}$ The Cochrane Collaboration is undertaking a systematic review of the effects of treatments in the management of acne that are currently considered complementary or alternative.

\section{What physical treatments are available?}

Physical treatments for acne include comedone extraction, chemical peels and microdermabrasion, intralesion corticosteroid injection for acne cysts, and high-intensity, narrowband blue light photodynamic therapy, as well as injectable fillers and laser resurfacing for acne scarring. However, there is limited evidence in peer-reviewed literature to support such treatments. ${ }^{3,44}$ The results of small pilot studies have supported the use of chemical peels, ${ }^{45}$ and some evidence suggests that corticosteroid injections are helpful for treating large inflammatory lesions. ${ }^{46}$

\section{How should children and pregnant women be treated?}

The treatment of acne in children is similar to that in adults. Because topical therapies may be more irritating in children, initiation with low concentrations is preferred. Systemic treatments should be reserved for more extensive cases. Erythromycin is preferred over tetracyclines for children under nine years of age, because tetracyclines can affect growing cartilage and teeth.

Although treatment with isotretinoin has numerous potential minor side effects in patients of all ages, an uncommon complication in young patients is premature epiphyseal closure.$^{38}$ This generally occurs when isotretinoin is administered in high doses, thus limiting long-term therapy.

Selecting appropriate treatment in pregnant women can be challenging because many acne therapies are teratogenic; all topical and especially oral retinoids should be avoided..$^{38}$ Oral therapies such as tetracyclines and antiandrogens are also contraindicated in pregnancy. Topical and oral treatment with erythromycin may be considered.

\section{What's new in treating acne?}

Trials are being conducted with currently available therapies, in different strengths and combinations. Combining an allylamine antifungal agent with benzoyl peroxide may prove to enhance the effectiveness of benzoyl peroxide in treating acne while preventing antibiotic resistance. ${ }^{18}$ Topical dapsone 5\% gel is a newer option for treating acne. A large multicentre randomized controlled trial in adolescents with acne found that when the gel was applied twice daily on the affected areas, $40 \%$ of the treatment group and $28 \%$ of the placebo group $(p<0.001)$ achieved the desired outcome at 12 weeks. ${ }^{47}$ The same trial and an additional study found that topical dapsone $5 \%$ gel is a safe treatment option in patients with a deficiency in glucose-6-phosphate dehydrogenase. ${ }^{48}$

More studies are needed to resolve the long-standing con- 
troversy about the role of diet and acne. As well, further direct treatment comparison and long-term trials are needed to determine the optimal sequence of treatment selection as well as to establish the effects on quality of life and long-term efficacy.

This review was solicited and has been peer reviewed

Competing interests: None declared.

\section{REFERENCES}

1. Magin P, Adams J, Heading G, et al. Psychological sequelae of acne vulgaris: results of a qualitative study. Can Fam Physician 2006;52:978-9.

2. Haider A, Shaw JC. Treatment of acne vulgaris. JAMA 2004;292:726-35.

3. Strauss JS, Krowchuk DP, Leyden JJ, et al. Guidelines of care for acne vulgaris management. J Am Acad Dermatol 2007;56:651-63.

4. James WD. Acne. N Engl J Med 2005;352:1463-72.

5. American Association of Clinical Endocrinologists Polycystic Ovary Syndrome Writing Committee. American Association of Clinical Endocrinologists position statement on metabolic and cardiovascular consequences of polycystic ovary syndrome. Endocr Pract 2005;11:126-34.

6. Gollnick H, Cunliffe W, Berson D, et al. Management of acne: a report from a globa alliance to improve outcomes in acne. J Am Acad Dermatol 2003;49(Suppl 1):S1-37.

7. Webster GF, Guenther L, Poulin YP, et al. A multicenter, double-blind, randomized comparison study of the efficacy and tolerability of once daily tazarotene $0.1 \%$ gel and adapalene $0.1 \%$ gel for the treatment of facial acne vulgaris. Cutis 2002;69 (Suppl):4-11.

8. Cunliffe WJ, Poncet M, Loesche C, et al. A comparison of the efficacy and tolerability of adapalene $0.1 \%$ gel vs tretinoin $0.025 \%$ gel in patients with acne vulgaris: a meta analysis of five randomized trials. Br J Dermatol 1998;139(suppl 52):48-56.

9. Hughes BR, Norris JF, Cunliffe WJ. A double-blind evaluation of topical isotretinoin $0.05 \%$, benzoyl peroxide gel $5 \%$ and placebo in patients with acne Clin Exp Dermatol 1992;17:165-8.

10. Mills OH Jr, Kligman AM, Pochi P, et al. Comparing 2.5\%, 5\%, and $10 \%$ benzoyl peroxide on inflammatory acne vulgaris. Int J Dermatol 1986;25:664-7.

11. Esterly NB, Furey NL, Flanagan LE. The effect of antimicrobial agents on leukocyte chemotaxis. J Invest Dermatol 1978;70:51-5.

12. Cunliffe WJ, Holland KT, Bojar R, et al. A randomized, double-blind comparison of a clindamycin phosphate/benzoyl peroxide gel formulation and a matching clindamycin gel with respect to microbiologic activity and clinical efficacy in the topical treatment of acne vulgaris. Clin Ther 2002;24:1117-33.

13. Zouboulis CC, Derumeaux L, Decroix J, et al. A multicentre, single-blind, randomized comparison of a fixed clindamycin phosphate/tretinoin gel formulation (Velac) applied once daily and a clindamycin lotion formulation (Dalacin T) applied twice daily in the topical treatment of acne vulgaris. Br J Dermatol 2000;143:498-505.

14. Handojo I. The combined use of topical benzoyl peroxide and tretinoin in the treatment of acne vulgaris. Int J Dermatol 1979;18:489-96.

15. Wolf JE Jr, Kaplan D, Kraus SJ, et al. Efficacy and tolerability of combined topical treatment of acne vulgaris with adapalene and clindamycin: a multicenter, randomized investigator blinded study. J Am Acad Dermatol 2003;49:S211-7.

16. Ellis CN, Leyden J, Katz HI, et al. Therapeutic studies with a new combination benzoyl peroxide/clindamycin topical gel in acne vulgaris. Cutis 2001;67(Suppl 2):13-20.

17. Bowe WP, Shalita AR. Effective over-the-counter acne treatments. Semin Cutan Med Surg 2008;27:170-6.

18. Burkhart CG, Burkhart CN. Treatment of acne vulgaris without antibiotics: tertiary amine-benzoyl peroxide combination vs. benzoyl peroxide alone (Proactiv Solution). Int J Dermatol 2007;46:89-93

19. Magin P, Pond D, Smith W, et al. A systematic review of the evidence for 'myths and misconceptions' in acne management: diet, face-washing and sunlight. Fam Pract 2005;22:62-70.

20. Oprica C, Nord CE. European surveillance study on the antibiotic susceptibility of Propionibacterium acnes. Clin Microbiol Infect 2005;11:204-13.

21. Masters PA, O'Bryan TA, Zurlo J, et al. Trimethoprim-sulfamethoxazole revisited. Arch Intern Med 2003;163:402-10.

22. Ozolins M, Eady EA, Avery AJ, et al. Comparison of five antimicrobial regimens for treatment of mild to moderate inflammatory facial acne vulgaris in the community: randomized controlled trial. Lancet 2004;364:2188-95.
23. Eady EA, Cove JH, Holland KT, et al. Erythromycin resistant propionibacteria in antibiotic treated acne patients: association with treatment failure. $\mathrm{Br} J$ Dermatol 1989;121:51-7.

24. Miller YW, Eady EA, Lacey RW, et al. Sequential antibiotic therapy for acne promotes the carriage of resistant staphylococci on the skin of contacts. J Antimicrob Chemother 1996;38:829-37.

25. Vowels BR, Yang S, Leyden JJ. Induction of proinflammatory cytokines by a soluble factor of propionibacterium acnes: implications for chronic inflammatory acne. Infect Immun 1995;63:3158-65.

26. Golub LM, Lee HM, Ryan ME, et al. Tetracyclines inhibit connective tissue breakdown by multiple non-antimicrobial mechanisms. Adv Dent Res 1998;12:12-26.

27. Ross JI, Snelling AM, Carnegie E, et al. Antibiotic resistant acne: lessons from Europe. Br J Dermatol 2003;148:467-78.

28. Eady AE, Cove JH, Layton AM. Is antibiotic resistance in cutaneous propionibacteria clinically relevant? Implications of resistance for acne patients and prescribers. Am J Clin Dermatol 2003;4:813-31.

29. Samuelson JS. An accurate photographic method for grading acne: initial use in a double-blind clinical comparison of minocycline and tetracycline. J Am Acad Dermatol 1985;12:461-7.

30. Cibula D, Hill M, Vohradnikova $\mathrm{O}$, et al. The role of androgens in determining acne severity in adult women. Br J Dermatol 2000;143:399-404.

31. Worret I, Arp W, Zahradnik HP, et al. Acne resolution rates: results of a singleblind, randomized, controlled, parallel phase III trial with EE/CMA (Belara) and EE/LNG (Microgynon). Dermatology 2001;203:38-44.

32. Rosen MP, Breitkopf DM, Nagamani M. A randomized controlled trial of secondversus third-generation oral contraceptives in the treatment of acne vulgaris. Am J Obstet Gynecol 2003;188:1158-60.

33. ACOG practice bulletin no.110: noncontraceptive uses of hormonal contraceptives. Obstet Gynecol 2010;115:206-18.

34. Van Vloten WA, van Haselen CW, van Zuuren EJ, et al. The effect of 2 combined oral contraceptives containing either drospirenone or cyproterone acetate on acne and seborrhea. Cutis 2002;69(supp14):2-15.

35. Goodfellow A, Alaghband-Zadeh J, Carter G, et al. Oral spironolactone improves acne vulgaris and reduces sebum excretion. Br J Dermatol 1984;111:209-14.

36. Miller JA, Wojnarowska FT, Dowd PM, et al. Anti-androgen treatment in women with acne: a controlled trial. Br J Dermatol 1986;114:705-16.

37. Shaw JC, White LE. Long-term safety of spironolactone in acne: results of an 8year follow-up study. J Cutan Med Surg 2002;6:541-5.

38. Wolverton SE. Comprehensive dermatologic drug therapy. 2nd ed. Philadelphia: WB Saunders; 2007.

39. Health Canada. Health Canada endorsed important safety information on Accutane Roche isotretinoin). Available http://hc-sc.gc.ca/dhp-mps/medeff/advisoriesavis/prof/2010/accutane_2_hpc-cps-eng.php (accessed 2010 Sep. 7).

40. Hull PR, D'Arcy C. Isotretinoin use and subsequent depression and suicide. Am J Clin Dermatol 2003;4:493-505

41. Product monograph. Accutane Roche. Mississauga (ON): Hoffmann-La Roche. 2010

42. Layton AM, Knaggs $\mathrm{H}$, Taylor J, et al. Isotretinoin for acne vulgaris-10 years later: a safe and successful treatment. Br J Dermatol 1993;129:292-6.

43. Bassett IB, Pannowitz DL, Barnetson RS. A comparative study of tea-tree oil versus benzoyl peroxide in the treatment of acne. Med J Aust 1990;153:455-8.

44. Jordan R, Cummins CCL, Burls A, et al. Laser resurfacing for facial acne scars. Cochrane Database of Systematic Reviews 2001, Issue 1. Art. No. CD001866. DOI:10.1002/14651858.CD001866.

45. Grimes PE. The safety and efficacy of salicylic acid chemical peels in darker racial-ethnic groups. Dermatol Surg 1999;25:18-22.

46. Levine RM, Rasmussen JE. Intralesional corticosteroids in the treatment of nodulocystic acne. Arch Dermatol 1983;119:480-1.

47. Raimer S, Maloney JM, Bourcier M, et al. United States/Canada Dapsone Gel Study Group. Efficacy and safety of dapsone gel $5 \%$ for the treatment of acne vulgaris in adolescents. Cutis 2008;81:171-8.

48. Piette WW, Taylor S, Pariser D, et al. Hematologic safety of dapsone gel, 5\%, for topical treatment of acne vulgaris. Arch Dermatol 2008;144:1564-70.

Correspondence to: Dr. Anatoli Freiman, Division of

Dermatology, University of Toronto, Women's College Hospital,

76 Grenville St., 8th floor, Toronto, ON M5S 1B2;

anatoli.freiman@gmail.com 